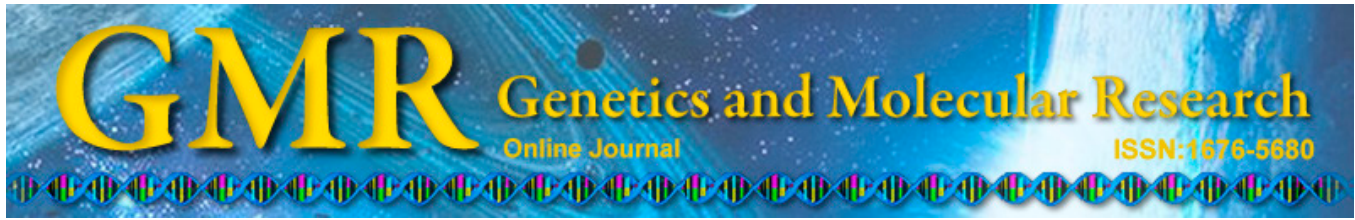

\title{
Assessment of genetic diversity and relationships among wild and cultivated Tunisian plums (Prunus spp) using random amplified microsatellite polymorphism markers
}

H. Ben Tamarzizt, S. Ben Mustapha, G. Baraket, D. Abdallah and A. Salhi-Hannachi

Laboratory of Molecular Genetics, Immunology \& Biotechnology, Faculty of Sciences of Tunis, University of Tunis El Manar, El Manar, Tunis, Tunisia

Corresponding author: A. Salhi-Hannachi

E-mail: Amel.SalhiHannachi@fsb.rnu.tn

Genet. Mol. Res. 14 (1): 1942-1956 (2015)

Received January 8, 2014

Accepted July 8, 2014

Published March 20, 2015

DOI http://dx.doi.org/10.4238/2015.March.20.4

ABSTRACT. The usefulness of random amplified microsatellite
polymorphism markers to study the genetic diversity and relationships
among cultivars belonging to Prunus salicina and $P$. domestica and
their wild relatives (P. insititia and P. spinosa) was investigated. A total
of 226 of 234 bands were polymorphic $(96.58 \%)$. The 226 random
amplified microsatellite polymorphism markers were screened using 15
random amplified polymorphic DNA and inter-simple sequence repeat
primers combinations for 54 Tunisian plum accessions. The percentage
of polymorphic bands ( $96.58 \%)$, the resolving power of primers values
(135.70), and the polymorphic information content demonstrated the
efficiency of the primers used in this study. The genetic distances
between accessions ranged from 0.18 to 0.79 with a mean of 0.24 ,
suggesting a high level of genetic diversity at the intra- and interspecific
levels. The unweighted pair group with arithmetic mean dendrogram 
and principal component analysis discriminated cultivars efficiently and illustrated relationships and divergence between spontaneous, locally cultivated, and introduced plum types. These procedures showed continuous variation that occurs independently of the status of the species and geographical origin of the plums. In this study, random amplified microsatellite polymorphism was found to be as a reliable molecular marker for fingerprinting and for examining the diversity study of the plum and its relatives.

Key words: Genetic diversity; Prunus domestica; Prunus insititia; Random amplified microsatellite polymorphism; Prunus salicina; Prunus spinosa

\section{INTRODUCTION}

The genus Prunus (Rosaceae, subfamily Prunoideae) is composed of 5 subgenera, including Prunophora, Amygdalus, Cerasus, Padus, and Laurocerasus (Badenes and Prafitt, 1995; Aradhya et al., 2004), which all originated mainly in the Northern hemisphere and are widely represented in Europe (Casas et al., 1999). This genus includes nectarine, peach, cherries, plum, apricot, and almond. More than 430 species are distributed mainly in north temperate regions of the world (Pandey et al., 2008). The basic chromosome number for Prunus is $\mathrm{x}=8$. Diploid, tetraploid, and hexaploid plum species are present within the subgenus Prunophora (Kester and Asay, 1975; Weinberger, 1975). The European plum (Prunus domestica L.), is hexaploid whereas Japanese plum, Prunus salicina is diploid (Badenes and Prafitt, 1995). Prunocerasus species such as Prunus americana, Prunus hortulana, and Prunus rivularis hybridize naturally, not only with themselves but also with species in the genus Prunus, and thus the potential for developing better-adapted varieties is large (Shaw and Small, 2004); however, this makes the botanical classification of the species controversial (Dosba et al., 1994). Several clonal rootstocks for stone fruit species have been released (Moreno et al., 1995a,b), and some are currently under extensive commercial exploitation. Desirable quality traits in the species have been selected (Salesses et al., 1994), including resistance to root knot nematode (Meloidogyne spp) (Scotto La Massèse et al., 1984). Plum characterization is of particular interest because the species has been domesticated independently on 3 different continents (Europe, America, and Japan) (Nassi et al., 2003) because of their adaptation to many ecogeographic conditions. Genetic erosion, resulting from the loss of numerous precious varieties, was increased through cultural practices as monovarietal culture and the extension of plant diseases such as coryneum caused by the fungus Coryneum beijerinckii or virus diseases caused by 2 ilarviruses, Prunus necrotic ringspot virus and prune dwarf virus, which infect plum orchards (Boulila and Marrakchi, 2001).

In Tunisia, plums (Prunus spp), characterized by their large adaptive capacities to numerous environments and soils, grow in northern Tunisian. Cultivated for their edible fruits, these plants are preferentially propagated using the grating method. This tree constitutes an important fruit crop and includes several elite cultivars. The local genetic resources of plum are important in the fruit industry and can be consumed fresh or dried. Unfortunately, as occurs in many other crop plants, the genetic base of indigenous and wild species of Tunisian plums is being eroded because of habitat destruction, introduction of outside cultivars/varieties, and lack 
of appropriate conservation and management strategies. Genetic diversity of plum cultivars has been evaluated through the use of morphological and pomological parameters according to the International Plant Genetic Resources Institute descriptors (IPGRI/CEC, 1984). Different environmental influences can affect these morphological characteristics. Polymorphisms were assessed using molecular markers, and several molecular markers were tested to identify cultivars and describe genetic diversity. Previous studies used biochemical and molecular markers such as isozymes (Chyi and Weeden, 1984) and restriction fragment length polymorphism (RFLP) (Shimada, 1996). Random amplified polymorphic DNA (RAPD)-amplified fragment length polymorphism (AFLP) markers have also been used to examine Prunus species not only for genetic diversity analysis but also for establishing genetic maps (Casas et al., 1999; Ben Tamarzizt et al., 2009). Goulão et al. (2001) used AFLPs and inter-simple sequence repeat (ISSR) markers to characterize both diploid and hexaploid plum cultivars. Simple sequence repeats were also established in nuclear and cytoplasmic DNA in Rosaceae species for molecular characterization (Howad et al., 2005; Ohta et al., 2005; Bouhadida et al., 2007). Thus, the aim of this study was to characterize 54 plum cultivars using 15 random amplified microsatellite polymorphism (RAMPO) combinations to evaluate the genetic diversity and to establish relationships among Tunisian plum cultivars. These markers were used to generate genetic fingerprints in plum species. Only a limited number of studies have been conducted to examine the genetic variation of plum species in Tunisia. There have been no reports describing the application of RAMPO markers for determining genetic diversity in Prunus species. Our results provide new insights into the evolutionary relationships among these species.

\section{MATERIAL AND METHODS}

\section{Plant materials}

A set of 54 Tunisian plum accessions, collected throughout Tunisia were analyzed in this study (Table 1, Figure 1). Among these, 7 are introduced varieties belonged to P. salicina and P. domestica species, 14 belonged to wild-type Prunus insititia and Prunus spinosa, and 33 were local cultivars ( $P$. salicina). Plant material was sampled from young leaves of adult trees and frozen at $-20^{\circ} \mathrm{C}$ for DNA extraction. Cultivated plums represent both the P. salicina and $P$. domestica species.

\section{Genomic DNA extraction}

Total cellular DNA was purified from young frozen leaves by using 2 procedures, including that described by Bernatzky and Tanksley (1986) and a modified procedure of Ahrens and Seemüller (1992). DNA quality was examined by electrophoresis on $0.8 \%$ agarose gels, as described by Sambrook et al. (1989), and DNA concentration was quantified spectrophotometrically.

\section{Primers and polymerase chain reaction (PCR) assays}

\section{Primers}

In this study, 2 types of primers were used. Initially, DNA amplification was conducted using 5 universal decamer oligonucleotides (OPH-11, OPA-2, OPA-18, OPM-1, and 
Table 1. List of the Tunisian plum accessions studied and their origins.

\begin{tabular}{|c|c|c|c|}
\hline Accession & Geographic origin & Native origin of variety & Species name \\
\hline Bedril & Ras Jebel & Local variety & Prunus salicina L. \\
\hline Bedri2 & Ras Jebel & Local variety & Prunus salicina L. \\
\hline Jabonia safra & Rafraf & Local variety & Prunus salicina $\mathrm{L}$. \\
\hline Janha & Rafraf & Local variety & Prunus salicina $\mathrm{L}$. \\
\hline Ain kounoulia & Rafraf & Local variety & Prunus salicina L. \\
\hline Ain bagra & Rafraf & Local variety & Prunus salicina L. \\
\hline Cidre1 & Rafraf & Local variety & Prunus salicina L. \\
\hline Cidre2 & Ghar el Melh & Local variety & Prunus salicina $\mathrm{L}$. \\
\hline Adham hmém & Rafraf & Local variety & Prunus salicina L. \\
\hline Neb zarouk & Rafraf & Local variety & Prunus salicina $\mathrm{L}$. \\
\hline Hamda & Rafraf & Local variety & Prunus salicina L. \\
\hline Sandid & Rafraf & Local variety & Prunus salicina L. \\
\hline Black diamond* & Menzel Bouzelfa & Introduced variety USA & Prunus salicina L. \\
\hline Golden Japan $1 *$ & El Alia & Introduced variety USA & Prunus salicina L. \\
\hline Golden Japan2* & Menzel Bouzelfa & Introduced variety USA & Prunus salicina L. \\
\hline Golden Japan3* & Ghar el Melh & Introduced variety USA & Prunus salicina L. \\
\hline Black Golden* & Kairouan & Introduced variety USA & Prunus salicina L. \\
\hline Santa Rosa1* & Rafraf & Introduced variety USA & Prunus salicina L. \\
\hline Santa Rosa2* & Menzel Bouzelfa & Introduced variety USA & Prunus salicina $\mathrm{L}$. \\
\hline Stanley* & Menzel Bouzelfa & Introduced variety USA & Prunus domestica $\mathrm{L}$. \\
\hline Meski hamra1 & Rafraf & Local variety & Prunus salicina $\mathrm{L}$. \\
\hline Meski hamra2 & Rafraf & Local variety & Prunus salicina L. \\
\hline Meski safra1 & Rafraf & Local variety & Prunus salicina L. \\
\hline Meski safra2 & Rafraf & Local variety & Prunus salicina L. \\
\hline Meski kahla1 & Rafraf & Local variety & Prunus salicina L. \\
\hline Meski kahla2 & Rafraf & Local variety & Prunus salicina L. \\
\hline Zaghwénia & Rafraf & Local variety & Prunus salicina L. \\
\hline Ain Tasstouria & Sounine & Local variety & Prunus salicina L. \\
\hline Ain Torkia & Rafraf & Local variety & Prunus salicina L. \\
\hline Ain Ben moussa & Rafraf & Local variety & Prunus salicina L. \\
\hline Ain Taher Noman & Rafraf & Local variety & Prunus salicina L. \\
\hline Bedri hamral & Menzel Bouzelfa & Local variety & Prunus salicina L. \\
\hline Bedri hamra2 & Kairouan & Local variety & Prunus salicina L. \\
\hline Bedri hamra3 & Kairouan & Local variety & Prunus salicina L. \\
\hline Bedri hamra4 & Kairouan & Local variety & Prunus salicina L. \\
\hline Baydha arbi & Rafraf & Local variety & Prunus salicina L. \\
\hline Aouina safra morra & Rafraf & Local variety & Prunus salicina L. \\
\hline Aouina hamra bedri & Rafraf & Local variety & Prunus salicina L. \\
\hline Aouina safra bedri & Rafraf & Local variety & Prunus salicina L. \\
\hline Safra Jridi & Rafraf & Local variety & Prunus salicina L. \\
\hline Sauvage** & Rafraf & Local origin & Prunus insititia L. \\
\hline Sauvage $1 * *$ & Thibar & Local origin & Prunus spinosa L. \\
\hline Sauvage $2 * *$ & Djebba & Local origin & Prunus spinosa L. \\
\hline Sauvage $3 * *$ & Djebba & Local origin & Prunus spinosa L. \\
\hline Zenou $1 * *$ & Douar Hamouda & Local origin & Prunus insititia L. \\
\hline Zenou2** & Douar Hamouda & Local origin & Prunus insititia L. \\
\hline Zenou3** & Douar Hamouda & Local origin & Prunus insititia L. \\
\hline Zenou $4 * *$ & Douar Hamouda & Local origin & Prunus insititia L. \\
\hline Zenou $5^{* *}$ & Douar Hamouda & Local origin & Prunus insititia L. \\
\hline Zenou6** & Douar Hamouda & Local origin & Prunus insititia L. \\
\hline Zenou 7** & Douar Hamouda & Local origin & Prunus insititia L. \\
\hline Jelya $1 * *$ & Bejou & Local origin & Prunus insititia L. \\
\hline Jelya2** & Bejou & Local origin & Prunus insititia $\mathrm{L}$. \\
\hline Chaaraouiya** & Ghar el Melh & Local origin & Prunus insititia L. \\
\hline
\end{tabular}

*Introduced varieties; **Wild-type.

OPM-5) purchased from Operon Technology Inc. (Huntsville, AL, USA) used to perform RAPD assays and 3 primers $(02,04$, and 05$)$ that were complementary to simple sequence repeats used to perform ISSR assays (Table 2). According to Chatti et al. (2007) and Rhouma et al. (2008), the RAMPO method consists of the combination of 2 PCR steps. 


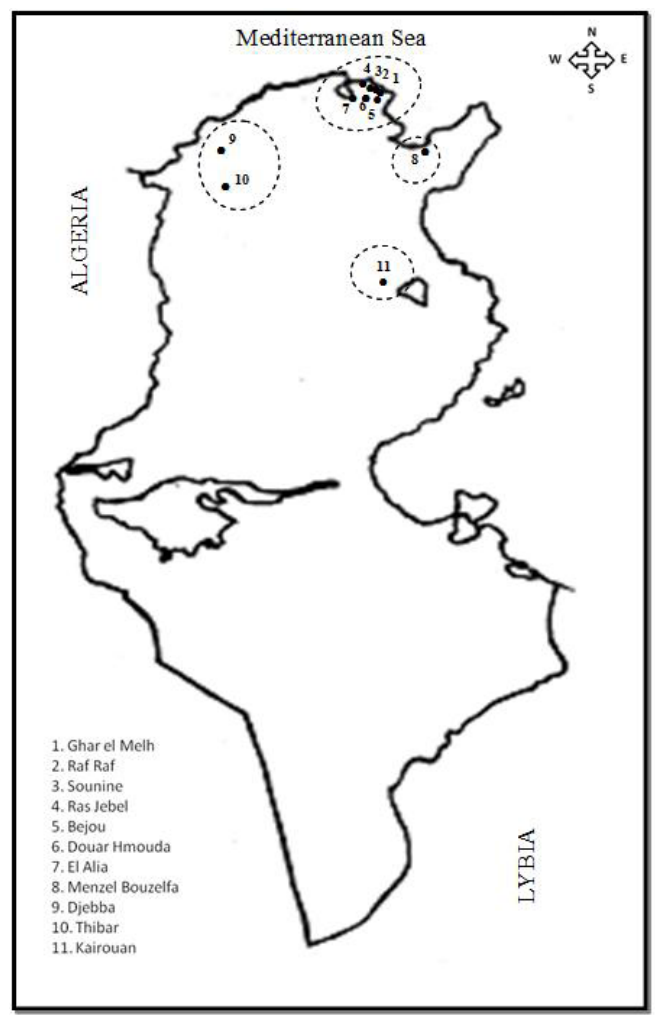

Figure 1. Map of Tunisia. Geographical distribution of the plums analyzed.

Table 2. Characteristics of the primers used in this study.

\begin{tabular}{lllc}
\hline Primer & Label & Sequence 5'-3' & Tm $\left({ }^{\circ} \mathrm{C}\right)$ \\
\hline RAPD & OPH-11 & CTTCCGCAGT & $35^{\circ}$ \\
& OPA-2 & TGCCGAGCTG & $35^{\circ}$ \\
& OPA-18 & AGGTGACCGT & $35^{\circ}$ \\
& OPM-1 & GTTGGTGGCT & $35^{\circ}$ \\
OPM-5 & GGGAACGTGT & $35^{\circ}$ \\
ISSR & 02 & $\left(\right.$ AG) ${ }_{10} \mathrm{~T}$ & $57^{\circ}$ \\
& 04 & $(\mathrm{CT}){ }_{10}^{\circ} \mathrm{A}$ & $60^{\circ}$ \\
\hline
\end{tabular}

\section{PCR assays}

Initially, RAPD-PCRs were carried out in a final volume of $25 \mu \mathrm{L}$ according to Ben Tamarzizt et al. (2009). ISSR-PCRs were performed in a $25-\mu \mathrm{L}$ reaction mixture volume containing $2 \mu \mathrm{L}$ RAPD-PCR products, $120 \mathrm{pg}$ primer, $200 \mu \mathrm{M}$ of each dNTP (DNA polymerization mix, Pharmacia, Orsay, France), $2.5 \mu \mathrm{L}$ 10X Taq DNA polymerase buffer, and 1.5 U Taq DNA polymerase (Q-Biogéne, Strasbourg, France). Amplifications were carried out in a DNA thermocycler (TC 512, Techne, Cambridge, UK) using the following temperatures cycles: an initial denaturation at $94^{\circ} \mathrm{C}$ for $5 \mathrm{~min}, 30$ cycles consisting 
of $30 \mathrm{~s}$ at $94^{\circ} \mathrm{C}$ for denaturation, $90 \mathrm{~s}$ at the corresponding annealing temperature $\left({ }^{\circ} \mathrm{C}\right)$, and $90 \mathrm{~s}$ at $72^{\circ} \mathrm{C}$ for elongation. The last cycle was followed by a final incubation for 5 min at $72^{\circ} \mathrm{C}$ and the PCR products were stored at $4{ }^{\circ} \mathrm{C}$ before analysis. Two independent RAMPO reactions were performed for each DNA sample to ensure the reproducibility of the generated banding patterns. Master mixes of the reaction constituents were used to reduce cross-contamination and variation in the amplification reactions. A negative control (reaction mix without DNA) was also included. Amplification of nuclear DNA products was evaluated by electrophoresis on $1.5 \%$ agarose gels in $0.5 \mathrm{x}$ Tris-Borate-EDTA buffer, $\mathrm{pH}$ 8.3, stained using ethidium bromide, and visualized under ultraviolet light (Sambrook et al., 1989). Amplified fragment sizes were estimated with a 1-kb ladder DNA marker (Invitrogen, Carlsbad, CA, USA).

\section{Data analysis}

The presence (1) or absence ( 0 ) of bands was scored to determine the total number of bands. Only polymorphic bands were taken into account and used to calculate the percentage of polymorphic bands. For each primer combination, the ability to discriminate cultivars was assessed by estimating the resolving power $(\mathrm{R} p)$ that has been described to correlate strongly with the ability to distinguish between accessions (Prevost and Wilkinson, 1999) according to the formula described by Gilbert et al. (1999):

$$
\mathrm{R} p=\sum \mathrm{Ib}, \text { where } \mathrm{Ib}=1-(2 \times|0.5-\mathrm{p}|)
$$

(Equation 1)

where $p$ is the proportion of accessions containing the band I.

Polymorphic information content (PIC) was estimated using the formula described by Lynch and Walsh (1998):

$$
P I C=1-\sum_{i=1}^{k} \mathbf{P i}^{2}
$$

where $k$ is the total number of alleles detected for a given marker locus and $P i$ is the frequency of the ith allele in the set of genotypes investigated.

A binary data matrix was obtained and computed using the Genedist program (version 3.572c) with the program PHYLIP (phylogeny inference package, version 3.5c) (Felsenstein, 1995) to produce a genetic distance matrix using the formula described by Nei and Li (1979). To test the usefulness of the overall information provided by the RAMPO data for establishing phylogenetic relationships between plums, cluster analysis was performed using the unweighted pair group with arithmetic mean (UPGMA) method. The UPGMA dendrogram was constructed using PHYLIP (Phylogeny Inference Package, version 3.5c) (Felsenstein, 1995) and the Treeview software of Page 1996 (Win32, version 1.5.2). Principal component analysis (PCA), as a multivariate analysis method, was applied using the XLSTAT program (2009) to determine the distribution and genetic relationships among plum accessions. 


\section{RESULTS}

\section{Primer resolving power and polymorphism}

Fifteen primer combinations generated clear and reproducible bands scored as RAMPO markers (Table 3). A total of 234 RAMPO fragments were consistently resolved and 226 were polymorphic ranging in size from 200 to 2500 base pairs (Figure 2). The number

Table 3. Primer combinations, percentage of polymorphic bands (PPB), resolving power (Rp), and polymorphism information content (PIC) of the tested primers.

\begin{tabular}{|c|c|c|c|c|c|}
\hline Primer combination & Total No. of bands & Polymorphic bands & PPB (\%) & $\mathrm{R} p$ & PIC \\
\hline OPH-11x02 & 16 & 16 & 100 & 9.51 & 0.81 \\
\hline OPH-11x04 & 15 & 13 & 86.66 & 6.74 & 0.85 \\
\hline OPH-11x05 & 13 & 11 & 84.61 & 5.29 & 0.87 \\
\hline OPA- $2 \mathrm{x} 02$ & 17 & 17 & 100 & 11.74 & 0.79 \\
\hline OPA-2x04 & 15 & 15 & 100 & 10.66 & 0.85 \\
\hline OPA- $2 \times 05$ & 21 & 19 & 90.47 & 11.18 & 0.84 \\
\hline OPA-18x02 & 20 & 20 & 100 & 12.25 & 0.85 \\
\hline OPA-18x04 & 15 & 15 & 100 & 10.03 & 0.85 \\
\hline OPA-18x05 & 15 & 15 & 100 & 7.51 & 0.79 \\
\hline OPM-1x02 & 14 & 13 & 92.85 & 8.40 & 0.85 \\
\hline OPM-1x04 & 14 & 13 & 92.85 & 8.33 & 0.87 \\
\hline OPM-1x05 & 10 & 10 & 100 & 6.18 & 0.69 \\
\hline OPM- $5 \mathrm{x} 02$ & 18 & 18 & 100 & 9.29 & 0.87 \\
\hline OPM- $5 \times 04$ & 16 & 16 & 100 & 7.92 & 0.88 \\
\hline OPM-5x05 & 15 & 15 & 100 & 10.59 & 0.75 \\
\hline Total & 234 & 226 & - & 135.7 & - \\
\hline Average & 15.6 & 15.06 & 96.49 & 9.04 & 0.82 \\
\hline
\end{tabular}
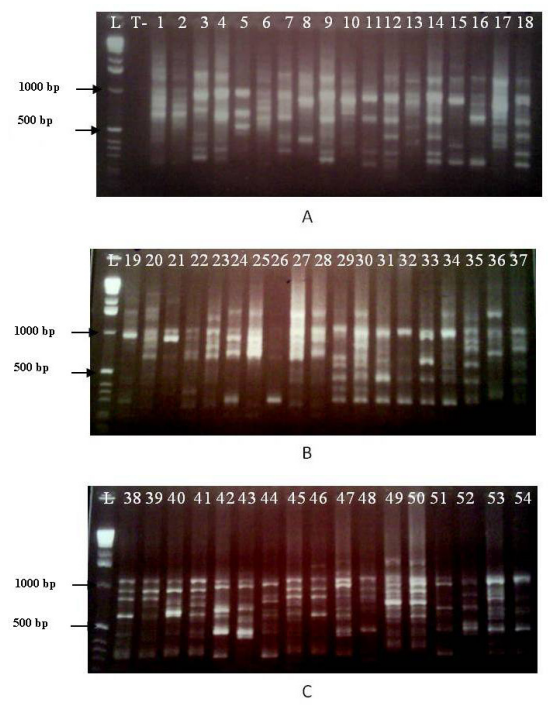

Figure 2. Polymorphism in DNA samples of plums and random amplified microsatellite polymorphism (RAMPO) fingerprints generated by OPA-18x02 (A), OPA-18x04 (B), and OPA-18x05 (C) primer combinations. These primer combinations produced clear and unambiguous bands. Lane $=$ ladder $(1 \mathrm{~kb}$, Invitrogen); lane $T$ - = negative control; lanes 1-54 = amplification patterns for accessions studied. 
of markers varied from 10 (OPM-1x05) to 20 (OPA-18x02), with a mean of 15.06 bands per primer combination. The percentage of polymorphic bands was high and varied from $84.61 \%$ for OPH-11x05 to $100 \%$ for the OPH-11x02, OPA-2x02, OPA-2x04, OPA-18x02, OPA-18x04, OPA-18x05, OPM-1x05, OPM-5x02, OPM-5x04, and OPM-5x05 primer combinations, with an average of $96.49 \%$. Thus, all primers tested were considered to be sufficiently powerful to detect DNA polymorphisms in plum accessions, as demonstrated by the highest value of $R p$ calculated for the tested primers. Indeed, the $R p$ rate varied from $5.29(\mathrm{OPH}-11 \mathrm{x} 05)$ to 12.25 (OPA-18x02), with a mean 9.04 (Table 3). In contrast, as shown in Figure 3, the PIC values varied from 0.69 to 0.88 , with a mean of 0.82 . In fact, 154 of the 226 RAMPOs exhibited PIC values ranging from 0.8 to 1 . Thus, the OPA- $18 \times 02$ combination products showing the higher number of polymorphic bands was the most efficient primer combination for revealing the genetic diversity of plum trees.

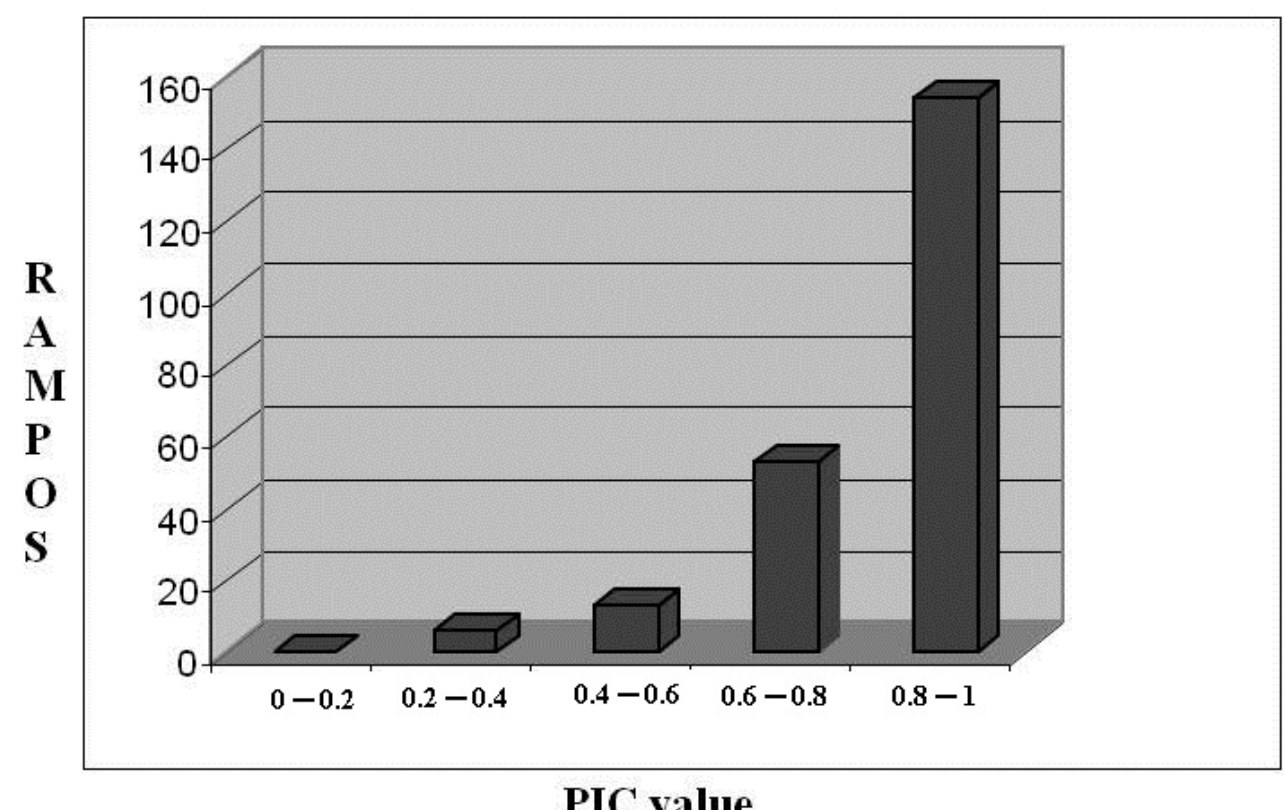

Figure 3. Distribution of random amplified microsatellite polymorphism (RAMPO) markers obtained considering the polymorphism information content (PIC) for plum accessions studied and frequency distribution of PIC range values.

\section{Genetic diversity and phylogenetic relationships}

Polymorphic RAMPO bands were scored as present (1) or absent (0) across all 54 genotypes for each primer-pair combination and used as a binary data matrix. Using the Nei and $\mathrm{Li}$ (1979) formula, a genetic distance matrix was constructed. The genetic distances ranged from 0.18 to 0.79 , with a mean of 0.24 , suggesting a high level of polymorphism recorded at the genomic DNA level of the accessions studied. For Prunus species, a good range of PIC value was observed (0.8-1), demonstrating the significant genetic diversity among plum accessions. 


\section{Intra and interspecific diversity}

The lowest distance value of 0.18 was observed between the Bedri hamra2 and Bedri hamra3 cultivars, which appeared to be closely related as they showed the same denomination, suggesting homonymy. The highest distance of 0.79 was calculated between the Golden Japan3 and Zaghwénia accessions, suggesting their divergence.

Cluster analysis of plum cultivars revealed strongly distinct genotypes from different geographical regions. The topology of the UPGMA dendrogram (Figure 4) showed the classification of varieties into 2 main clusters: the first one labeled (a) contained local cultivars

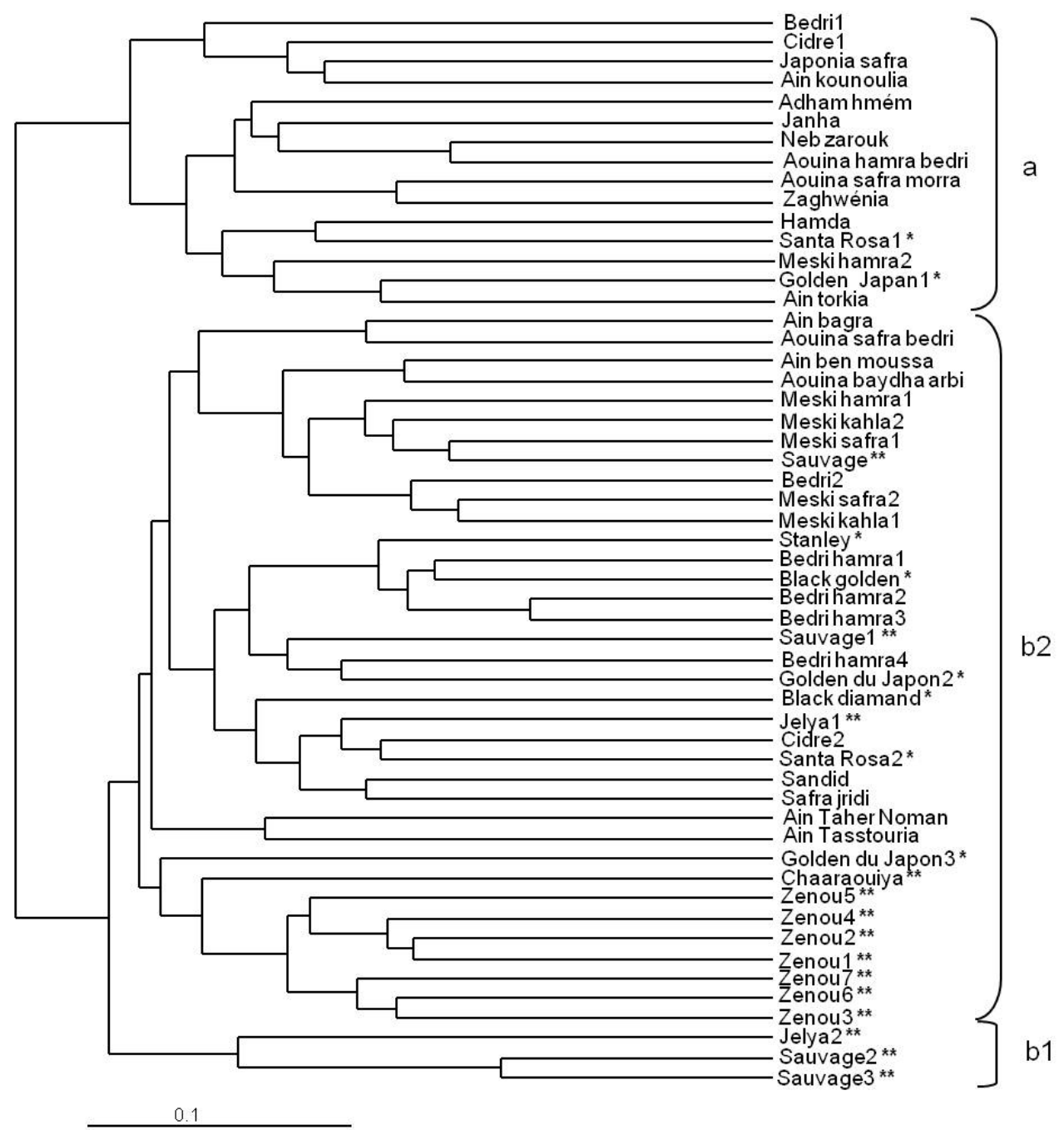

Figure 4. Unweighted pair group method with arithmetic mean (UPGMA) dendrogram illustrating the genetic relationships between 54 Tunisian plum accessions based on random amplified microsatellite polymorphism (RAMPO) markers. *Introduced varieties; **Wild-type (Prunus insititia and Prunus spinosa). 
collected from Rafraf and Ras Jebel: Bedri1, Cidre1, Japonia safra, Ain kounoulia, Adham hmém, Janha, Neb zarouk, Aouina hamra bedri, Aouina safra morra, Zaghwénia, Hamda, Meski hamra2, and Ain torkia and two introduced varieties: Santa Rosa1 and Golden Japan1. The second group was divided into 2 major subgroups, (b1) and (b2), which contained the remaining accessions analyzed from Douar Hamouda, Rafraf, Ras Jebel, Bejou, Ghar el Melh, Sounine, El Alia, Thibar, Djjeba, Cap Bon (North), and Kairouan (Center). The first subgroup (b1), significantly divergent, contained 3 wild genotypes belonging to the $P$. insititia species Sauvage 2 and Sauvage3, which originated from Djjeba and Jelya 2 from Bejou. The second subgroup (b2) included cultivars and wild types originating from all prospected locations. Thus, no complete eco-geographical clustering was observed within these subgroups. Typically, continuous genetic diversity characterized local plum germplasm. Additionally, wild cultivars named Zenou were grouped together and clustered with plum cultivars representing the $P$. domestica or $P$. salicina species. However, cultivars with the same appellation were distinguished using RAMPO markers, including Bedri, Meski, Cidre, and Golden Japan (Figure 4 and Figure 5). Our results suggest the presence of intra-varietal and intra-specific diversity. In fact, these plums belonged to the $P$. salicina species. The results of the study are important for accurate identification of elite genotypes in breeding programs.

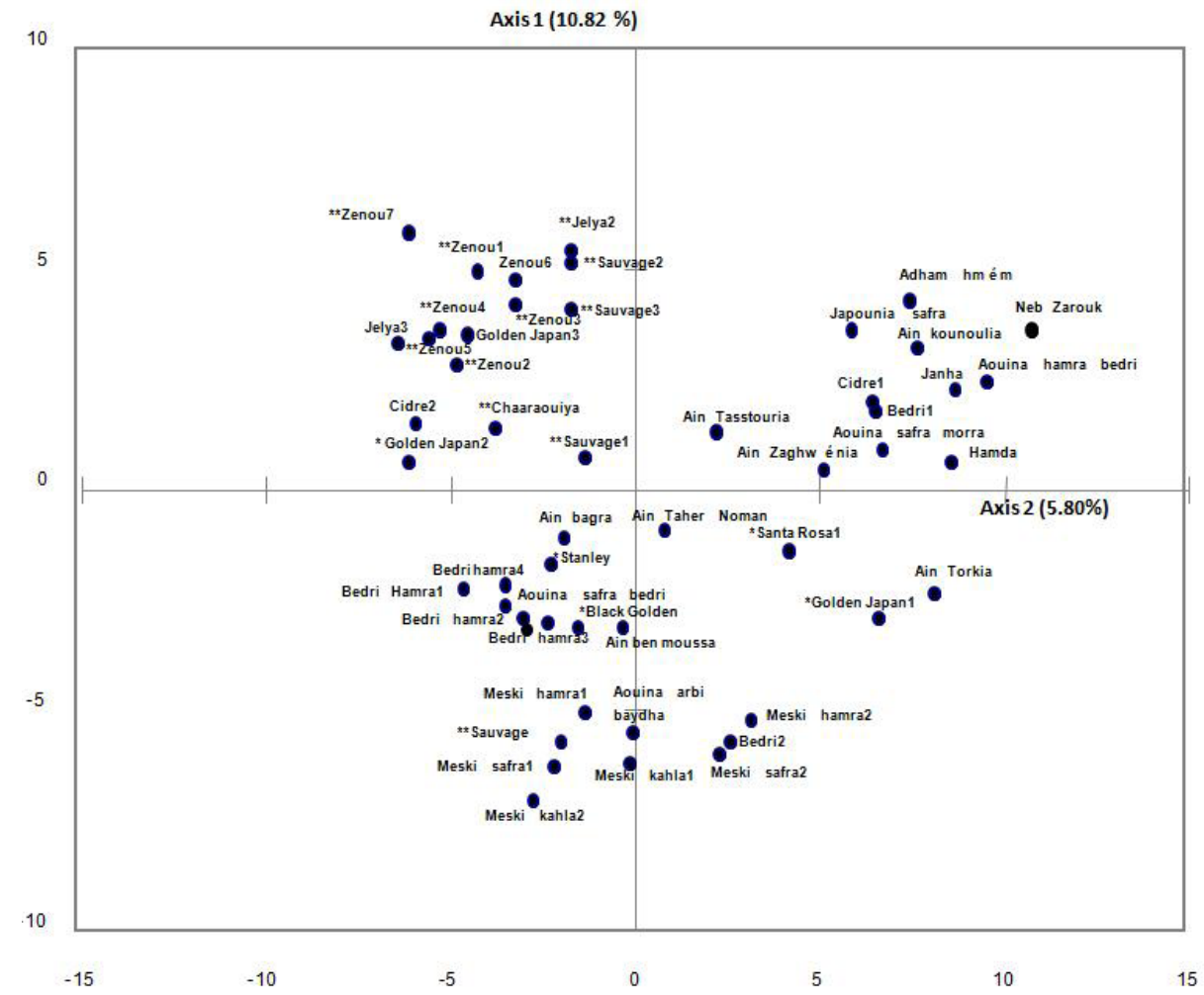

Figure 5. Dispersion of 54 Tunisian plum accessions in the plot (1-2) of the principal component analysis based on 226 random amplified microsatellite polymorphism markers. Local cultivars (Prunus salicina); *Introduced varieties ( $P$. salicina and $P$. domestica); **Wild-type ( $P$. insititia and $P$. spinosa) 
Additionally, multivariate PCA based on the RAMPO data (Figure 5) showed similar results as cluster analysis. Groupings of plum genotypes using PCA were based mainly on the first 3 axes, which accounted for $21.76 \%$ of the variability observed. These 3 axes accounted for $10.81,5.80$, and $5.140 \%$ of the observed diversity, respectively, for PC1, PC2, and PC3. The variables integrated positively by PC1 were markers generated by the primer combinations OPH-11 $\mathrm{x} 05$, OPA-2x05, and OPM-5x05. This first component was negatively correlated with markers generated by the OPA2x02 combination. The second axis was positively correlated with markers generated by the OPA-2x02, OPA-2x04, OPA-2x05, and OPA-18x05 combinations and negatively with those produced by OPH-11x04, OPM-1x02, and OPM$5 \times 04$. Our results suggest that the distribution of cultivars occurs independently from their geographic origin and species status.

\section{Genetic diversity between cultivated and wild-type plums}

In the dendrogram, all plum accessions clustered into 2 main groups (a and b). Group a consisted of 15 cultivated plum of $P$. salicina. The other 39 accessions were included in group b (Figure 4). Group b could be divided into 2 subgroups. Subgroup b1 included 3 wild-type species ( 1 P. insititia, 2 P. spinosa). The remaining 36 accessions were classified as sub-group b2, which included 11 wild trees representing $P$. insititia and $P$. spinosa and 25 cultivated plum of $P$. salicina and $P$. domestica. PCA was used to efficiently discriminate the cultivars and illustrated the relationships and divergence between spontaneous, locally cultivated, and introduced plum types. Discrimination of spontaneous trees was clearly noted for 3 trees representing the sub-cluster b1. Interestingly, the first axis of PCA permitted the separation of wild-type from cultivated species. Additionally, an important homogeneity between introduced and local accessions was observed, confirming the results of previous studies (Casas et al., 1999; Shimada et al., 1999; Baránek et al., 2006; Ayanoglu et al., 2007; Ben Tamarzizt et al., 2009).

\section{DISCUSSION}

In this study, RAMPO markers were used to examine the genetic diversity of cultivated and wild plum accessions as well as to establish relationships between the 2 compartments to understand the origin of Tunisian plum germplasm. A relatively high level of genetic diversity was observed in both the wild and cultivated gene pools.

The genetic diversity of plum cultivars was assessed using a set of 15 primer combinations, which gave rise to 234 bands. Additionally, the high collective R $p$ rate obtained (135.7) indicated the efficiency of the primers. In fact, these primers generated 226 polymorphic bands of 234 fragments, with a mean of 15.6 per primer pair. This is significantly higher than values reported in other studies based on RAPD markers in plum cultivars (Casas et al., 1999; Shimada et al., 1999; Baránek et al., 2006) and AFLP markers (Ayanoglu et al., 2007). Similar results were also observed for Tunisian plum shrubs using the RAPD technique (Ben Tamarzizt et al., 2009). Thus, for local plum germplasms, the RAMPO technique produced a larger number of markers compared with other techniques. The genetic distances calculated among the trees indicated high levels of molecular polymorphism. Similar results were obtained for other fruit trees, such as fig by Chatti et al. (2007) and date-palms by Rhouma et al. (2008). RAMPO suggests intravarietal diversity as demonstrated by discrimination of Bedri, Meski, 
Cidre, and Golden Japan cultivars. These may be considered as cases of misidentification or homonymy and suggest the presence of polyclonal varieties. These results agree with those of previous studies using RAPD markers such as a study conducted by Ben Tamarzizt et al. (2009). A common genetic basis characterizes the genotypes studied, despite of their morphological divergence and taxonomic status (Ben Tamarzizt et al., 2009).

UPGMA cluster analysis showed the presence of 2 major groups. The plum repartition occurred independently of the geographic origin of trees. Additionally, some wild trees were not differentiated from local plum, except Zenou1, Zenou2, Zenou3, Zenou4, Zenou5, Zenou6, and Zenou7 and Sauvage2 and Sauvage3, which had the same origins as Douar Hamouda and Djebba, respectively. However, the classification of cultivated ( $P$. domestica and $P$. salicina) and wild shrubs ( $P$. insititia and $P$. spinosa) obtained using the UPGMA dendrogram and PCA did not show strong discrimination between the 2 , indicating a unique origin. There was no distinction between Tunisian accessions and introduced samples characterized by powerful pomological and agronomical traits to demonstrate the performance of local cultivars. PCA showed a similar result, confirming those found using cluster analysis. In fact, we note the association between wild plums that were separated according to the first axis and other cultivars.

Similar results were reported by Ben Tamarzizt et al. (2009). This analysis demonstrated that cultivars clustered jointly, and those such as Santa Rosa1 and Santa Rosa2 and Golden Japan and Golden Japan2 belong to P. salicina (diploid $2 \mathrm{n}=16$ ); additionally, those grouped with cultivars Black Golden and Black diamond clustered with the Stanley cultivar, representing $P$. domestica (hexaploid $2 \mathrm{n}=48$ ). As demonstrated by Shimada et al. (1999), RAPD markers can be used to differentiate between the "Japanese plum group" $P$. salicina and the "European plum group" $P$. domestica. Thus, continuous genetic diversity characterizes plum species cultivars. It is widely thought that the hexaploid European plums $P$. domestica and $P$. insititia arose from a cross between a diploid $(2 \mathrm{n}=2 \mathrm{x}=16)$ cherry plum or myrobalan, Prunus cerasifera, and a tetraploid $(2 \mathrm{n}=4 \mathrm{x}=32)$ sloe or blackthorn, $P$. spinosa (Crane and Lawrence, 1952). However, another hypothesis based on RFLP variation in cpDNA genes suggested that the European plum might have originated from polyploid forms of the myrobalan plum (Reynders and Salesses, 1991). Both hypotheses agree with our findings and the levels of genetic similarities among diploid and hexaploid plums. Despite their economic and genetic values, no detailed study has been conducted to evaluate the extent and pattern of genetic diversity within plum species in its native distributional range. The only available information regarding these important plant genetic resources pertains to molecular (RAPD) and a morphological characterization (Ben Tamarzizt et al., 2009).

Detailed characterization and evaluation, including molecular analysis of genetic diversity, therefore, is needed to assess the conservation requirements and utilitarian prospects of plum species. Assessment of genetic diversity using morphological markers alone has serious limitations, particularly in species of a complex genus such as Prunus, whose taxonomy is otherwise in a chaotic state because of frequent incidences of hybridization and polyploidy. RAMPO markers revealed the narrow genetic diversity on which domesticated accessions are based by clustering a set of cultivars and wild types together. The results showed that molecular markers are useful for studying intra- and inter specific genetic diversity in plums and describing the diversity and hybridization events within plum gene pools during their history. Plum has complicated ploidy levels and show different parentages in natural hybridization between species. Natural hybridization and introgression occur widely in plants and play important roles in their evolution (Jarvis and Hodgkin, 1999). Hybridization is of great interest in 
plant evolutionary studies because it generates new genotypes, thus, increasing genetic polymorphism, which may lead to new adaptations (Rieseberg, 1991) and the formation of new ecotypes, or species, as suggested by Rieseberg (1997) and Soltis and Soltis (1999). These new combinations of genes resulting from hybridization and introgression between wild relatives and their crop cultivars are important in the evolution of domesticated crop species (Jarvis and Hodgkin, 1999).

The RAMPO technique often reveals a much larger number of polymorphic markers for assessing genetic diversity in plum cultivar identification, in the management of germplasm resources, and for molecular differentiation of plum germplasm resources of Tunisia. In this study, we conducted extensive sampling from the plum natural habitat to assess RAMPO and genetic variability in the species $P$. domestica and $P$. salicina as well as the closely related wild species $P$. insititia and $P$. spinosa present in the northern regions of Tunisia. In conclusion, RAMPO markers can be successfully used to determine the level and structure of plum genetic diversity. The relationships among cultivated and spontaneous genotypes studied from different geographical regions may reveal the proximity between the two gene pools and indicate the relatively of genetic differentiation between the genotypes, which may have resulted from an inherently narrow genetic base from which the plum was domesticated, combined with historical migration of germplasm, and natural hybridization.

\section{CONCLUSIONS}

This is the first study examining the characterization of Prunus species based on RAMPO markers as a molecular markers. We found that the molecular markers could be used to study genetic diversity and distribution within and among a set Prunus species (P. salicina, $P$. domestica, $P$. insititia, and $P$. spinosa). This study revealed the rich genetic diversity among plum accessions and indicated that RAMPO markers can be used to identify fruit resources and to explain their genetic diversity. RAMPO markers revealed the narrow genetic diversity among wild ( $P$. insititia and $P$. spinosa) and cultivated species (P. salicina and P. domestica) and indicated that the molecular classification was not consistent with geographic origin or taxonomic status. Identification of intra and interspecific diversity is an important pre-requisite for promoting genetic diversity analysis. A larger sample throughout the distribution area of plums should be examined in order to detect and quantify the prevalent genetic diversity existing within and inter plum species at the molecular level. Wide genetic diversity is of great importance for developing improved varieties and estimating gene flow between cultivated species and wild-type species. Analyzing genetic diversity may be useful for designing effective breeding programs to broaden the genetic base of commercially grown varieties and plum improvement practices. To estimate the extent of variation in the plum germplasm between ecogeographical groups and related species, our results are useful for planning breeding programs involving diversity analysis, cultivar identification, or marker-assisted selection. The RAMPO database can be used for better management, conservation, resource utilization of plums.

\section{ACKNOWLEDGMENTS}

Research supported by grants from the Tunisian Ministère de l'Enseignement Supérieur et de la Recherche Scientifique. 


\section{REFERENCES}

Ahrens U and Seemüller E (1992). Detection of DNA of plant pathogenic mycoplasma-like organisms by a polymerase chain reaction that amplifies the sequence of the 16S rRNA gene. Phytopathology 82: 828-832.

Aradhya MK, Weeks C and Simon CJ (2004). Molecular characterization of variability and relationships among seven cultivated and selected wild species of Prunus L. using amplified fragment length polymorphism. Sci. Hortic. 103: 131-144.

Ayanoglu H, Bayazit S, Inan G, Bakir M, et al. (2007). AFLP analysis of genetic diversity in Turkish green plum accessions (Prunus cerasifera L.) adapted to the Mediterranean region. Sci. Hortic. 114: 263-267.

Badenes ML and Prafitt ED (1995). Phylogenetic relationships of cultivated Prunus species from analysis of chloroplast DNA variation. Theor. Appl. Genet. 90: 1035-1041.

Baránek M, Raddová J and Pidra M (2006). Comparative analysis of genetic diversity in Prunus L. as revealed by RAPD and SSR markers. Sci. Hortic. 108: 253-259.

Ben Tamarzizt H, Baraket G, Ben Mustapha S, Marrakchi M, et al. (2009). Genetic relatedness among Tunisian plum cultivars by random amplified polymorphic DNA analysis and evaluation of phenotypic characters. Sci Hortic. 121: 440-446.

Bernatzky R and Tanksley SD (1986). Genetics of actin-related sequences in tomato. Theor. Appl. Genet. 72: 314-321.

Bouhadida M, Casas AM, Moreno MA and Gogorcena Y (2007). Molecular characterization of Miraflores peach variety and relatives using SSRs. Sci. Hortic. 111: 140-145.

Boulila M and Marrakchi M (2001). Detection and characterization of stone fruit virus diseases in Tunisia. Phytopathol. Mediterr. 40: 125-136.

Casas AM, Igartua E, Balaguer G and Moreno MA (1999). Genetic diversity of Prunus rootstocks analysed by RAPD markers. Euphytica 110: 139-149.

Chatti K, Saddoud O, Salhi-Hannachi A, Mars M, et al. (2007). Analysis of genetic diversity and relationships in a Tunisian fig (Ficus carica) germplasm collection by random amplified microsatellite polymorphisms. J. Integr. Plant Biol. 49: 386-391.

Chyi YF and Weeden NF (1984). Relative isozyme band intensities permit the identification of the $2 \mathrm{n}$ gamete parent of triploid apple cultivars. Hortic. Sci. 19: 818-819.

Crane MB and Lawrence WJ (1952). The Genetics of Garden Plants. 4th edn. Macmillan, New York.

Dosba F, Bernhard FR and Zanetto A (1994). Importance des ressources génétiques des Prunus. Comptes rendus de l'Académie d'Agriculture de France 80: 45-57.

Felsenstein J (1995). Philogeny Interference Package (PHYLIP). Version 3.5 c. Department of Genetics, University of Washington, Seattle.

Gilbert JE, Lewis RV, Wilkinson MJ and Galigari PDS (1999). Developing and appropriate strategy to assess genetic variability in plant germplasm collections. Theor. Appl. Genet. 98: 1125-1131.

Goulão L, Monte-Corvo L and Oliveira CM (2001). Phenetic characterization of plum cultivars by high multiplex ratio markers: amplified fragment length polymorphisms and intersimple sequence repeats. J. Am. Soc. Hort. Sci. 126: $72-77$.

Howad W, Yamamoto T, Dirlewanger E, Testolin R, et al. (2005). Mapping with a few plants: using selective mapping for microsatellite saturation of the Prunus reference map. Genetics 171: 1305-1309.

IPGRI (International Board for Plant Genetic Resources) and CEC (Commission of European Communities) (1984). Descriptor list for plum and allied species. In: (Cobianchi D and Watkins R, eds.), Committee on disease resistance breeding and use of gene banks. CEC Secretariat, Brussels, pp. 31.

Kester DE and Asay RA (1975). Almonds. In: Advances in fruit breeding. (Janick J and Moore JN, eds). Purdue University Press, West Lafayette, pp. 285-335.

Jarvis DI and Hodgkin T (1999). Wild relatives and crop cultivars: detecting natural introgression and farmer selection of new genetic combinations in agroecosystems. Mol. Ecol. 8: S159-S173.

Lynch M and Walsh JB (1998). Genetics and Analysis of Quantitative Traits. Sinauer Associates. Inc., Sunderiand.

Moreno MA, Tabuenca MC and Cambra R (1995a). Adesoto 101, a plum rootstock for peaches and other stone fruit. Hortic. Sci. 30: 1314-1315.

Moreno MA, Tabuenca MC and Cambra R (1995b). Ademir, a myrobalan rootstock for plums. Hortic. Sci. 30: 1475-1476.

Nassi MO, Ruffa E, Me G, Leopri G, et al. (2003). A contribution to the systematic of a piedmontese plum ecotype. Plant Breeding 122: 532-535.

Nei M and Li WS (1979). Mathematical model for studying genetic variation in terms of restriction endonuclease. Proc. Natl. Acad. Sci. U. S. A. 76: 5269-5273. 
Ohta S, Nishitani C and Yamamoto T (2005). Chloroplast microsatellites in Prunus, Rosaceae. Mol. Ecol. 5: 837-840.

Pandey A, Nayar ER, Venkateswaran K and Bhandan C (2008). Genetic resources of Prunus (Rosaceae) in India. Genet. Resour. Crop Evol. 55: 91-104.

Prevost A and Wilkinson MJ (1999). A new system of comparing PCR primers applied to ISSR fingerprinting of potato cultivars. Theor. Appl. Genet. 98: 107-112.

Rhouma S, Dakhlaoui-Dkhil S, Ould Mohamed Salem A, Zehdi-Azouzi S, et al. (2008). Genetic diversity and phylogenic relationships in date-palms (Phoenix dactylifera $\mathrm{L}$.) as assessed by random amplified microsatellite polymorphism markers (RAMPOs). Sci. Hortic. 117: 53-57.

Reynders S and Salesses G (1991). Study on the relationships within the subgenus Prunophora. Restriction maps of the ribosomal genes in P. cerasifera and $P$. spinosa. Acta Hort. 283: 27-29.

Rieseberg LH (1991). Homoploid reticulate evolution in helianthus (Asteraceae): evidence from ribosomal genes. Amer. J. Bot. 78: 1218-1237.

Rieseberg LH (1997). Hybrid origins of plant species. Ann. Rev. Ecol. Syst. 28: 359-389.

Salesses G, Grassely C and Bernhard R (1994). Utilisation des espèces indigènes et exotiques pour l'amélioration des Prunus cultivés, variétés et porte-greffes. Comptes rendus de l'Académie d'Agriculture de France 80: 77-88.

Sambrook J, Fritsch EF and Maniatis T (1989). Molecular Cloning: A laboratory Manual, 2nd edn. Cold Spring Harbor Laboratory, Cold Spring Harbor.

Scotto La Massese C, Grassely C, Minot JC, Voisin R, et al. (1984). Differential response of 23 clones and hybrids of Prunus regarding four Meloidogyne species. Revue de Nématologie 7: 265-270.

Shaw J and Small RL (2004). Addressing the "hardest puzzle in American pomology": phylogeny of Prunus sect. Prunocerasus (Rosaceae) based on seven noncoding chloroplast DNA regions. Am. J. Bot. 91: 985-996.

Shimada T (1996). Studies on Phylogeny and Phyletic Evolution in Prunus Species. Doctoral thesis, University of Kobe, Hyogo.

Shimada T, Hayama H, Aji T, Yamaguchi M, et al. (1999). Genetic diversity of plums characterized by random amplified polymorphic DNA (RAPD) analysis. Euphytica 109: 143-147.

Soltis DE and Soltis PS (1999). Polyploidy: recurrent formation and genome evolution. Trends Ecol. Evol. 14: 348-352.

Weinberger JH (1975). Plums. In: Advances in Fruit Breeding, (Janick J and Moore JN, eds.). Purdue University Press, West Lafayette, pp. 336-347. 